\title{
Two-Stroke Low Speed Diesel Engine Simulation Model for NOx Analysis
}

\author{
Branko Lalića, Nikola Račića, Gojmir Radicab
}

All commercial marine engines have to comply with IMO regulations on emissions, especially of nitrogen oxides. This paper describes the gases produced in the combustion process in the diesel engine, and the manner of pollutant creation. Several models of slow-speed diesel engines have been developed and analysed. The characteristics of the simulation model are compared with the characteristics obtained on the testbed, and their differences considered. Using the term for the formation of NOx, as well as independently developed programs in MATLAB, the rate of nitrogen oxide formation was obtained as a function of excess air, pressure and temperature. The reduction of excess air increases adiabatic flame temperature and has an effect on NOx emissions. The obtained results are compared with the actual values measured on the testbed.

\section{KEY WORDS}

$\sim$ Marine two-stroke diesel engine

$\sim$ NOx emission

$\sim$ Internal combustion engine modelling a. University of Split, Faculty of Maritime Studies, Split, Croatia e-mail: blalic@pfst.hr

b. University of Split, Faculty of Electrical Engineering, Mechanical Engineering and Naval Architecture, Split, Croatia

e-mail: goradica@fesb.hr

This work is licensed under (cc) BY

\section{INTRODUCTION}

Exhaust gases from marine diesel engines are the primary source of emissions from ships and significantly contribute to environmental pollution due to the characteristics of the combustion process, typical for large marine two-stroke low speed engines and the use of heavy fuels. Ocean-going ships are the major contributors to global emissions of several hazardous air pollutants, such as nitrogen oxides (NOx), sulphur oxide (SOx), fine particulate matter (PM), hydrocarbons (HCs), carbon monoxide (CO) and greenhouse gas carbon dioxide $\left(\mathrm{CO}_{2}\right)$. These pollutants do not only have local, but global impact as well. While impact on local (or regional) air quality is mostly due to pollutants such as PM, NOx and sulphur, $\mathrm{CO}_{2}$ has impact on global climate. The quantity of gases emitted from marine engines into the atmosphere is directly related to the total fuel oil consumption. Regulations governing air pollution from merchant shipping are developed at the global level. Since shipping is inherently international in character, having uniform regulations on issues such as air emissions from ships is vital. The shipping industry is principally regulated by the International Maritime Organization (IMO), an UN agency based in London, responsible for the safety of life at sea and the protection of the marine environment. IMO ship pollution rules are contained in the "International Convention on the Prevention of Pollution from Ships", i.e. MARPOL 73/78, Annex VI - the first set of regulations on marine exhaust emissions. This paper analyses the effect of modification of an engine's characteristics on nitrogen oxide emissions (Komar and Lalić, 2015). Scappin (Scappin et al., 2012) attempts to develop a correlation to predict thermal NOx formation in compression ignition $(\mathrm{Cl})$ engine fuelled with diesel and biodiesel. Attention was paid to both fuel properties and engine design factors. NOx emissions predicted by the correlation were found to be comparable to the actually measured emissions. 
Saravanan (Saravanan et al., 2012) does something similar by developing a method for energy system analysis for low speed diesel marine engines to predict their performance and NOx emissions. The extended Zeldovich mechanism was used to predict the NOx emissions. An electronically controlled engine simulated to validate the model was found to be capable of predicting NOx emissions and specific fuel oil consumption with $95 \%$ confidence intervals. However, Larsenb et al. (Larsenb et al., 2015) study looked into two-stroke diesel machinery for ships, with five varying configurations to explore the trade-off between increased NOx emissions and reduction in fuel consumption. By implementing a waste heat recovery system using an organic Rankine cycle and a hybrid turbocharger, fuel consumption decreased by up to $9 \%$ and NOx up to $6.5 \%$. On the other hand, Andreadis (Andreadis et al., 2009) uses a large two-stroke marine diesel engine operating at full load to explore the pilot injection strategies using simulations of computational fluid dynamics along with an Evolutionary Algorithm. The solutions obtained were analysed and identified based on Pareto dominance. NOx emissions centred on early and late pilot injection improved. Guan (Guan et al., 2015) used a modular zero-dimensional engine model built in MatLab and Simulink environment to study the operation of large two-stoke marine diesel engines. Engine shop trial values were compared to the derived performance parameters of the engine, simulated under steady conditions, followed by the discussion of the operating strategies of the engine and their influence on $\mathrm{CO}_{2}$ emissions and fuel savings. The purpose of the Varbantes (Varbantes et. al., 2012) research is to highlight the methods improving diesel engine efficiency. The purpose of control is the even distribution of load between the cylinders, providing the fuel equipment and main diesel systems are operating as usual. The power plant capacity, fuel efficiency and compliance with MARPOL environmental restrictions depend on it. In their previous studies, the authors (Radica, Račić) explored the possibility of increasing the efficiency of a low speed two-stroke turbocharged main diesel engine operating with waste heat recovery by combined heat and power production (Grljušić et al., 2014; Grljušić et al., 2015). Paper (Spahni et al., 2015) deals with a different concept realisation of Generation $X$-engines, namely (X-tra efficiency, X-tra manufacturing-friendly, $X$-tra reliability, X-tra environmentally-friendly). The differences between engines W-X35, W-X40, W-X52, W-X62 W-X72, W-X82 and $\mathrm{W}-\mathrm{X} 92$ are due to differences in engine size, shipyard requirements or the availability of technical concepts.

\section{RESULTS AND DISCUSSION}

\subsection{The Formation of Thermal Nitrogen Oxides}

Although nitrogen monoxide $\mathrm{NO}$ and $\mathrm{NO}_{2}$ constitute the majority of nitrogen oxides NOx, nitrogen monoxide formed in combustion processes predominates. $\mathrm{NO}$ and $\mathrm{NO}_{2}$ create nitric oxide $\mathrm{N}_{2} \mathrm{O}$, nitrogen trioxide $\mathrm{N}_{2} \mathrm{O}_{3}$ and $\mathrm{N}_{2} \mathrm{O}_{5}$ nitrogen peroxide which is present in much smaller quantities. Although the oxidation of molecular nitrogen is the basis for the formation of NO, if fuel contains a substantial amount of nitrogen, the oxidation of the nitrogen components of the fuel functions as an additional source of NO. Diesel fuels contain higher percentage of nitrogen than petrol. Since NO is the primary product (over 90 $\%$ ) of combustion in diesel engines, its formation merits further clarification. The formation of thermal nitric oxide was described in (Heywood, 1988; McAllistar et al., 2011; Lalić et al., 2014; Lalić et al., 2016). The reactions required for the formation of NO from atmospheric nitrogen have been studied extensively. The following reactions show an almost stoichiometric combustion mixture of fuel and air to create NO from molecular nitrogen:

$$
\begin{aligned}
& \mathrm{N}_{2}+\mathrm{O} \leftrightarrow \mathrm{NO}+\mathrm{N} \\
& \mathrm{N}+\mathrm{O}_{2} \leftrightarrow \mathrm{NO}+\mathrm{O} \\
& \mathrm{N}+\mathrm{OH} \leftrightarrow \mathrm{NO}+\mathrm{H}
\end{aligned}
$$

This is often called the extended Zeldovich mechanism. Zeldovich was the first to recognize the importance of the first two reactions, while Lavoie added the third reaction which is of minor importance. The emergence of nitrogen oxides can be presented as shown in the following equation (McAllistar et al., 2011):

$$
\begin{aligned}
\frac{d_{x N O}}{d t} \cong & 1.476 \cdot 10^{21} \cdot x_{N_{2}} \cdot x_{O_{2}}^{0.5} \cdot \\
& e^{\left(\frac{-67520}{T}\right)} \cdot\left(\frac{P}{R \cdot T}\right)^{0.5} p_{p m s}{ }^{-1}
\end{aligned}
$$

Where $T$ is absolute temperature; $x_{N_{2}}$ is mole fraction of nitrogen; $x_{\mathrm{O}_{2}}$ is mole fraction of oxygen; $P$ is maximum pressure for the given temperature; $R$ is universal gas constant $\left(8314 \mathrm{Jkmol}^{-1} \mathrm{~K}^{-1}\right)$. The greatest influences on the formation of thermal nitrogen oxide $(N O)$ are local temperature in the combustion chamber $\left(T_{i}\right)$, pressure (influenced by the concentration of ingredients), local air surplus $\left(\lambda_{i}\right)$, retention time $\left(\tau_{i}\right)$ observed particles of composition in an area with conditions $\left(T_{i}\right)$ and $\left(\lambda_{i}\right)$. Figure 1 illustrates the dependence of nitric oxide (NO) formation speed on combustion temperature for a wide range of ratios of equality, and very small quantities of nitric monoxide (NO) are shown to be formed when combustion temperature is below $1800 \mathrm{~K}$. 


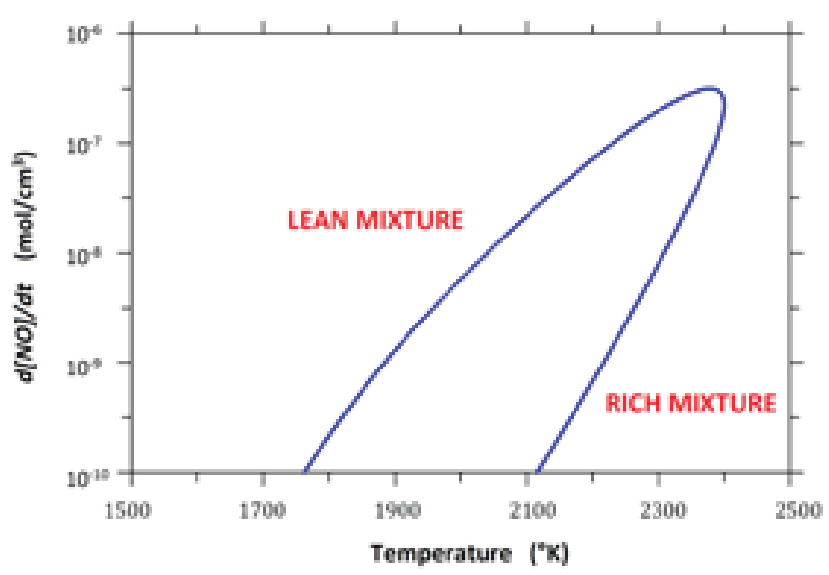

Figure 1.

Formation of nitric oxide (NO) in the function of mixture concentration and combustion temperature (McAllistar et al., 2011).

As shown in Figure 1, nitric oxide levels can be decreased by reducing the rate of reaction velocity, which lowers combustion temperature, and consequently, reduces oxygen $O$ and nitrogen $N$ levels. As for conditions of combustion in the engine, $\tau_{N O}$ is compared to the time it takes to change the conditions in the engine (equal or more), which means that the process is a kinetically controlled formation of NO.

$\tau_{N O}=\frac{8 \cdot 10^{-16} \cdot T \cdot e^{\left(\frac{58300}{T}\right)}}{P^{\frac{1}{2}}} S$

Where $\tau_{N O}$ is time of NO formation expressed in seconds.

\subsection{Low Speed Diesel Engine Model}

This type of slow speed marine diesel engine is an open system with input and output streams. In order to simplify the simulation, the engine was treated as a closed system in which the state of equilibrium was assumed to change in control volumes (quasi stationary model), while unsteady gas dynamic effects were neglected. A set of mathematical equations represents the mathematical model of attributes of physical processes, including parameters obtained by measuring or estimating the physical model. The cylinder pressure, temperature and gas composition are assumed to be equal in all cylinder chambers. Weight losses due to leaks are taken into consideration in the high-pressure part of the process, while kinetic energy is ignored.

\section{- INPUT PARAMETERS \\ - OUTPUT PARAMETERS}

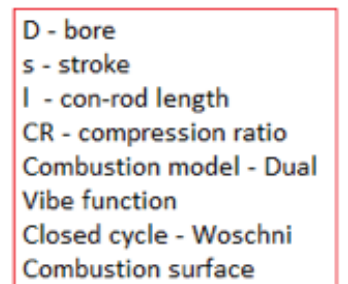

Combustion surface
Valve open (deg) Valve close (deg) Max lift MOP (deg)

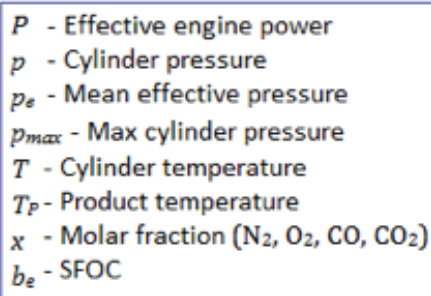

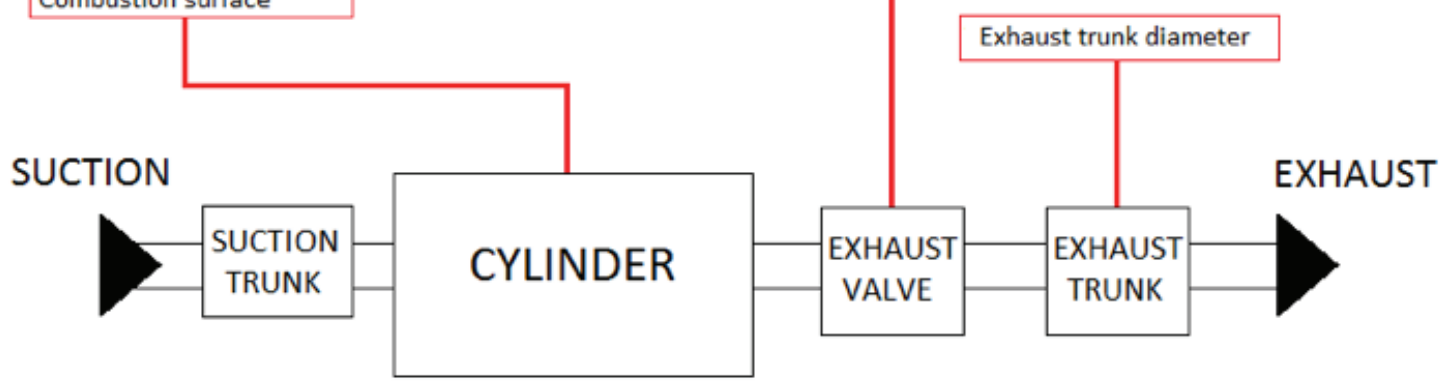

Figure 2.

Simplified working matter flows and influential model output parameters in low speed diesel engine. 
The heat in the cylinder is transferred by convection and later by radiation during combustion. Heat transfer coefficients are not the same throughout the cylinder, i.e. the temperature field is unsteady and inhomogeneous. Heat transferred to the cylinder walls is calculated for each crankshaft angle. Heat loss is described with Woschni's model, and the parameters of the law of combustion are determined by analytical form in the function of combustion according to Vibe (Radica, 2008).

\subsection{Calculation of Nitrogen Oxide Emissions}

Since the software package used was unable to simulate nitric oxide $\mathrm{NO}$ emissions, the estimated NO emissions needed to be calculated according to equation (2) (Benson, 1982). As M. Stoffels wrote in (Stoffels, 1999), the critical period of NO formation in diesel engines is marked by the moment of maximum combustion temperatures. The NO formation rate increases with the duration of combustion and growing pressure. Once maximum pressure is reached, the temperature of combusted gases decreases due to volume expansion and they begin to mix with cooler gases within the cylinder, resulting in decreasing $\mathrm{NO}$ emissions. The calculation of NO formation rate requires the establishment of the maximum temperature of combustion products. As stated in (Benson, 1982), the temperature of products will reach its maximum when there are no heat losses to the environment and when all the energy released in the combustion process is used to heat combustion products. This temperature is called the adiabatic flame temperature $\left(T_{A F T}\right)$ and an analysis of combustion at constant pressure is used for its calculation. Adiabatic flame temperature for poor mixture (for equivalence ratio $\Phi \leq 1$ ) is (Benson, 1982):

$T_{A F T}=T_{R}+\frac{\Phi \cdot f_{s} \cdot L H V}{\left(1+\Phi \cdot f_{s}\right) \cdot \bar{c}_{p, P}}$

Where $T_{R}$ is absolute temperature of the reactants, $\Phi$ is equivalence ratio, $f_{s}$ is stoichiometric fuel/air ratio, $L H V$ is fuel lower heat value, and $\bar{c}_{p, P}$ is mean specific heat capacity of products. Compression temperature at the moment of fuel injection, used as the temperature of the reactants $T_{R^{\prime}}$ is easily determined from the temperature diagram in Figure 3.

Mean specific heat capacity of products $\bar{c}_{p, P}$ is taken as the average temperature of reactants and products, which is:

$\bar{T}=\frac{T_{P}+T_{R}}{2}$

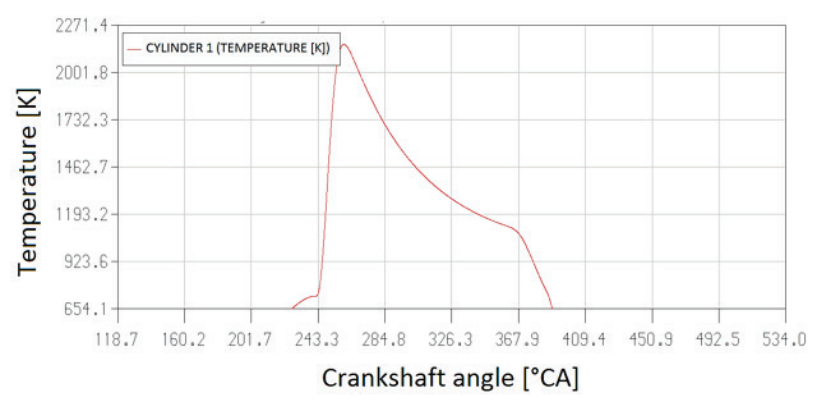

Figure 3.

Temperature in crankshaft angle function (MAN B\&W 6S50).

The temperature of the reactants may safely be assumed to be equal to exhaust temperature, since its change would not significantly affect the specific heat capacity. Assume that the temperature of products $T_{p}$ is $623 \mathrm{~K}$, or $350^{\circ} \mathrm{C}$. The average temperature of exhaust gas reactants and products $(\bar{T}=675 \mathrm{~K})$ can now be determined. The specific heat capacities of exhaust gas products for poor mixture are indicated in thermodynamics tables, i.e. Table 1.

Table 1.

Specific heat capacity of exhaust gas products.

\begin{tabular}{ll} 
Product & Specific heat capacity $\mathrm{kJkg}^{-1} \mathrm{~K}^{-1}$ \\
\hline Water $\mathrm{H}_{2} \mathrm{O}$ & 2.13 \\
\hline Carbon dioxide & 1.15 \\
\hline Oxygen $\mathrm{O}_{2}$ & 1.05 \\
\hline Nytrogen $\mathrm{N}_{2}$ & 1.12 \\
\hline
\end{tabular}

The mean value of the specific heat capacity of products $\bar{c}_{p, P^{\prime}}$ can be calculated by entering the heat capacities of combustion products indicated in the table into the following expression (Guan et al., 2015):

$\bar{C}_{p, P}=\frac{1}{N} \sum_{i=1}^{N} \bar{C}_{p, i P}=$

$\frac{C_{p, \mathrm{H}_{2} \mathrm{O}}+C_{p_{1} \mathrm{CO}_{2}}+C_{p, \mathrm{O}_{2}}+C_{p, \mathrm{~N}_{2}}}{4} \mathrm{kJkg}^{-1} \mathrm{~K}^{-1}$

Adiabatic flame temperature $\left(T_{A F T}\right)$ largely depends on the relative air/fuel ratio and compression ratio, elaborated 
in further text. The establishment of connection between adiabatic flame temperature and relative air/fuel ratio requires taking several relative air/fuel ratios into account. The ratios are obtained by calculating corresponding temperatures using the Matlab software package. Table 2 contains values required for the calculation of the adiabatic flame temperature. When these values are entered into Matlab, the values of the adiabatic flame temperature may be obtained depending on the relative air/fuel ratio. The dependence of adiabatic flame temperature $T_{\text {AFT }}$ range on the relative air/fuel ratio is shown in Figure 4. The diagram in Figure 4 suggests that as the increase in air surplus reduces the $T_{A F T}$, calculated by expression (6), there is simultaneously a clear increase in real fuel/air ratio ( $Z$ ), and a reduction in relative air/fuel ratio, i.e. an increase in fuel mass $(\mathrm{mg})$ within the cylinder reduces the relative air/fuel ratio. The increase in fuel mass in the cylinder is accompanied by an increase in temperature, and therefore an increase in energy. The increase in temperature is justified due to reduced air surplus.

Table 2.

Values required for TAFT calculation (MAN B\&W 6S50MC).

\begin{tabular}{ll} 
Parameter & Value \\
\hline Temperature of reactants $\mathrm{T}_{\mathrm{R}}$ & $727 \mathrm{~K}$ \\
\hline Relative fuel/air ratio $\lambda$ & $1.7-2.3$ \\
\hline Stehiometric fuel/air ratio $\mathrm{f}_{\mathrm{s}}$ & 0.069 \\
\hline Fuel lower heat value LHV & $42.7 \mathrm{MJkg}^{-1}$ \\
\hline Mean specific heat capacity of products $\overline{\mathrm{C}}_{\mathrm{p}, \mathrm{P}}$ & $1.363 \mathrm{kJkg}^{-1} \mathrm{~K}^{-1}$ \\
\hline
\end{tabular}

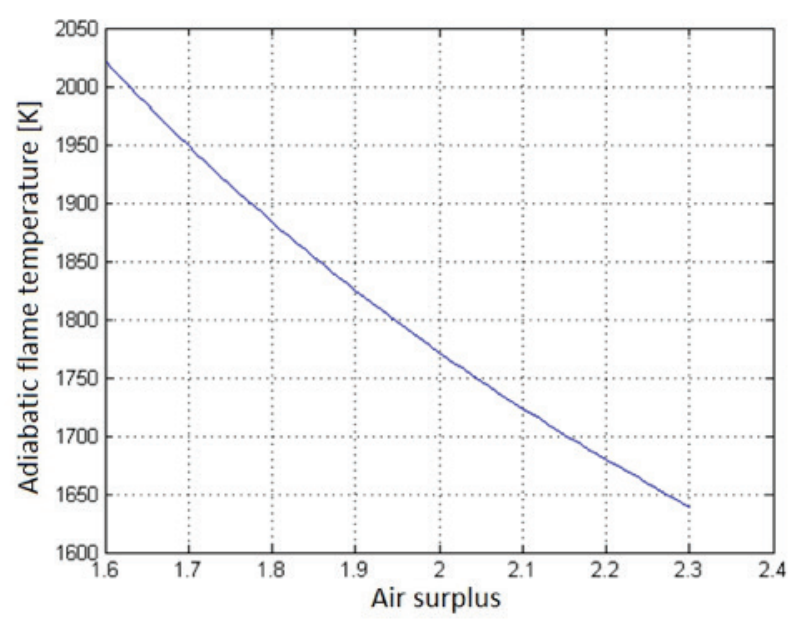

Figure 4.

Dependence of adiabatic flame temperature on air surplus (MAN B\&W 6S50).
Figure 3, obtained from the software package, can now be related to the resulting adiabatic flame temperature range and indicates a range of crankshaft degrees (on the abscissa) required for the pressure values, mole fraction of oxygen $\mathrm{O}_{2}$ and nitrogen $\mathrm{N}_{2}$. Their values are shown in the diagrams in Figure 5. Matlab was used to calculate the values and tabulate the diagrams shown. Using the expression (2) for the rate of production of $\mathrm{NO}$ and expression (3) for NO formation time, NO emission can be obtained. The rate of NO production is given in $\mathrm{ppm} / \mathrm{s}$, and formation time in seconds, i.e. the product of these two expressions is the value of $\mathrm{NO}$ emissions at a given time:

$x_{N O}=\frac{d x_{N O}}{d t} \cdot \tau_{N O} \quad p p m$

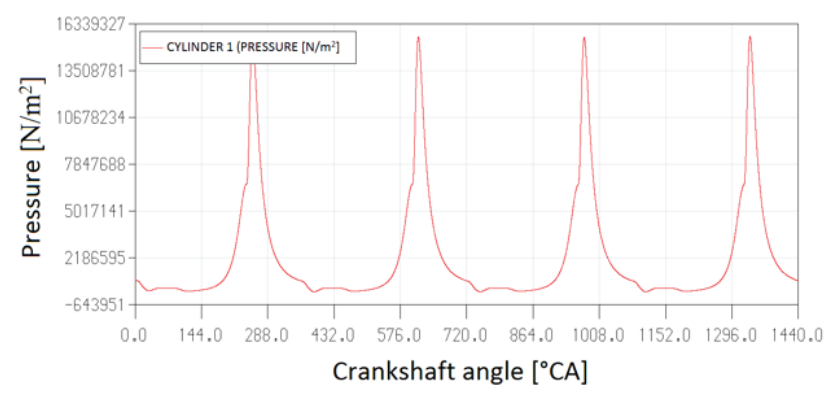

a)

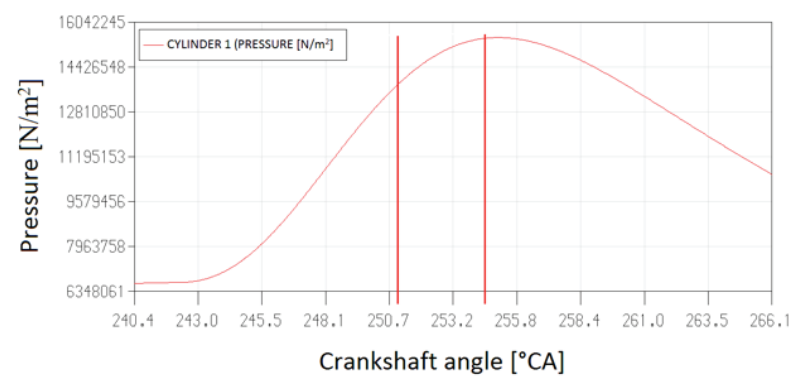

b)

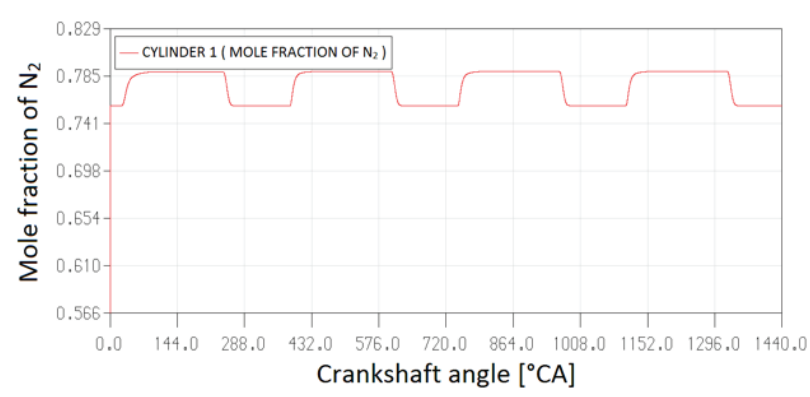

c) 


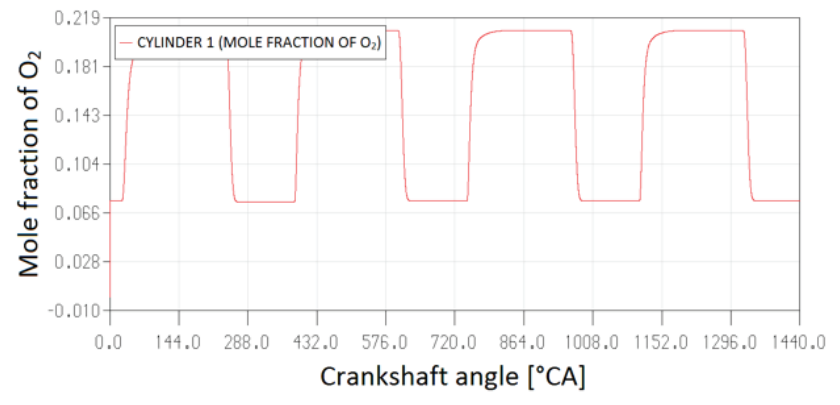

d)

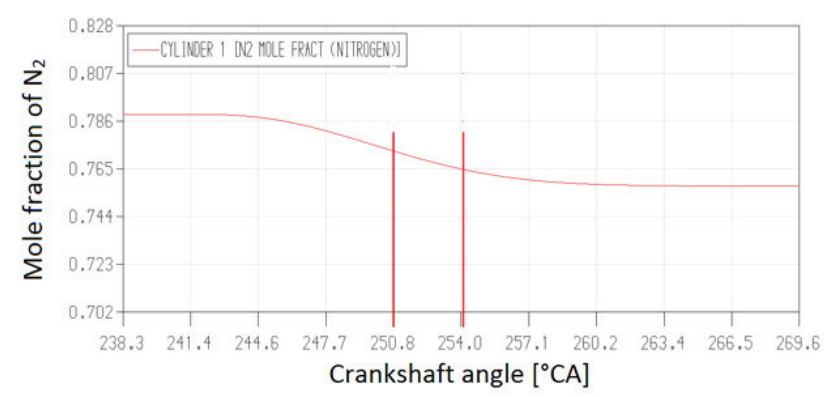

e)

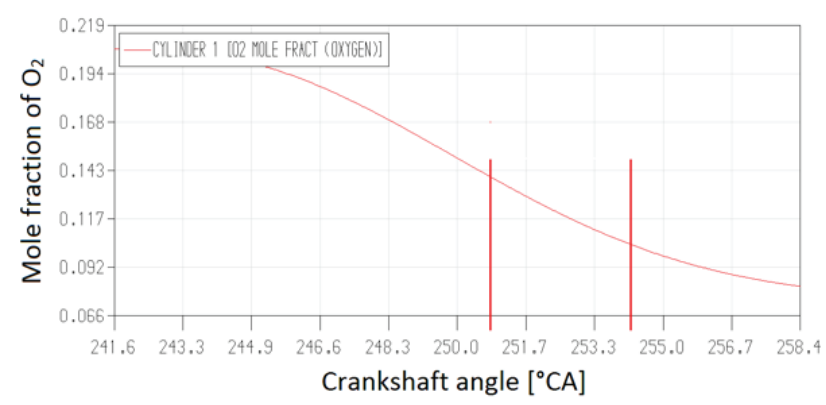

f)

Figure 5.

Dependence of parameters on the crankshaft angle: a) cylinder pressure; b) cylinder pressure for $\mathrm{T}_{\mathrm{AFT}}$ (within vertical lines); c) mole fraction of $\mathrm{N}_{2}$; d mole fraction of $\mathrm{O}_{2}$; ) Value of nitroen in the cylinder for $\mathrm{T}_{\text {AFT }}$ range (within vertical lines); $f$ ) Value of oxygen in the cylinder for $T_{\text {AFT }}$ range (within vertical lines).

When tabulated values of the model are entered in the expression (7), NO emission can be obtained, and shown as a function of temperature and pressure, Figure $6 a$ and $b$. The analysis will be conducted for two engines having the same characteristics, but different compression ratios and RPMs (crankshaft revolutions per minute). Since both engines are produced by the same manufacturer and are of the same type - MAN 6S50 MC - to prevent confusion they will be marked as:

Engine 1:

- Real compression ratio 13.21,

- RPM $121 \mathrm{~min}^{-1}$.

Engine 2:

- Real compression ratio 13.54,

- RPM $110 \mathrm{~min}^{-1}$.

So far, the analysed data pertains to Engine 1.

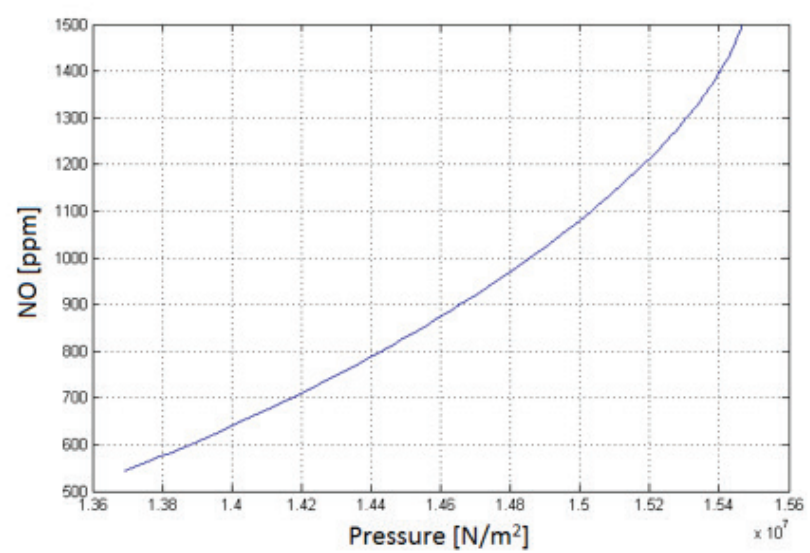

a)

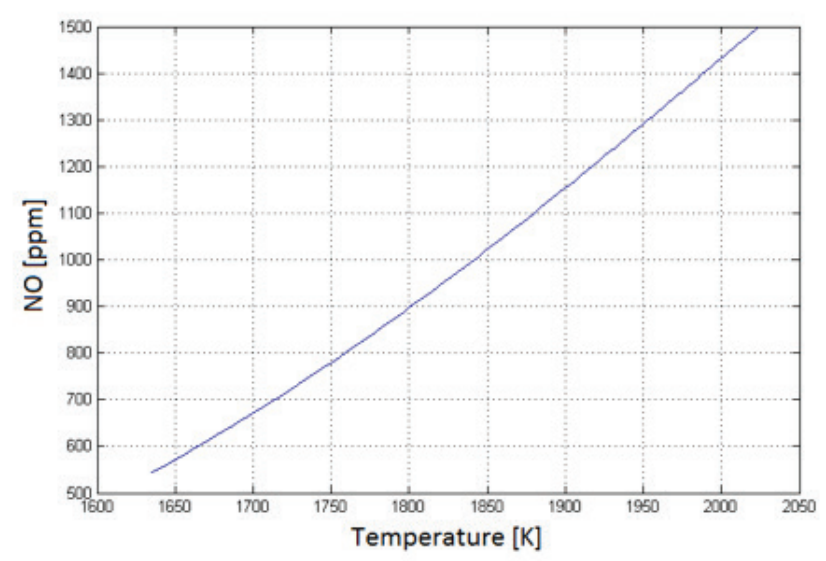

b)

Figure 6.

Nitrogen Oxide emission: a) as a function of pressure; b) as a function of temperature.

Comparison between Engine 1 and Engine 2 is illustrated in Figure 7. Values for Engine 2 are obtained as shown in the calculation procedure for Engine 1. 


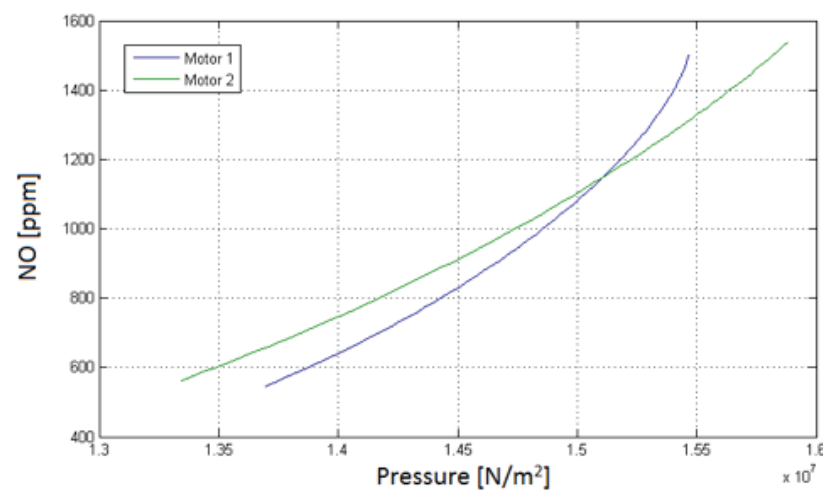

a)

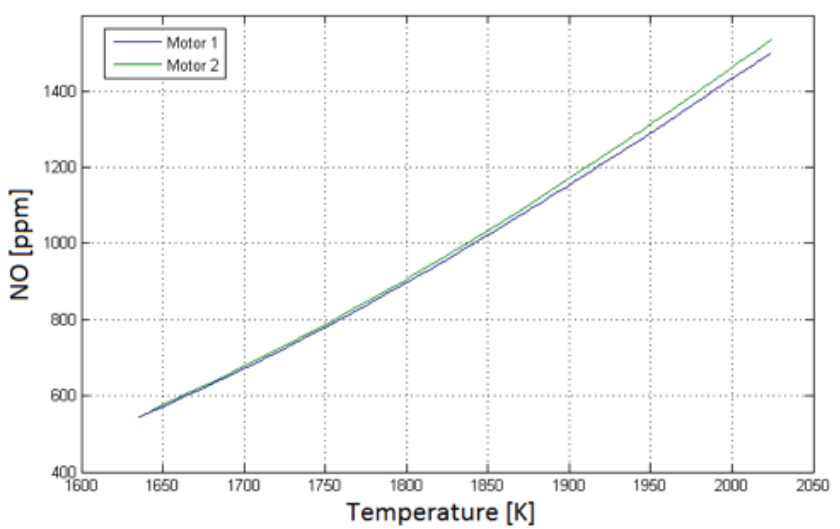

b)

Figure 7.

Nitrogen Oxide emissions: a) based on the pressures of engines no.1 \& 2; b) based on the temperatures of engines no.1 \& 2 .

Evidence of traceability data has increased compression ratio for each engine by 0.5 , which means:

- Engine 1: actual compression ratio 13.71, and

- Engine 2: actual compression ratio 14.04.

In Figure 8 all diagrams of engines with both initial and altered compression ratios are compared. Diagrams (b) and (c) illustrate the effect of compression ratio on $\mathrm{NO}$ emission volume. Compression temperature increases linearly with compression ratio increments, identified earlier in this paper as the temperature of the reactants $T_{R}$. Expression (6) suggests that the increment of reactant temperature also increases adiabatic flame temperature $\mathrm{T}_{\mathrm{AFT}}$. An increase in compression temperature is known to affect NO emission concentration. The preceding diagram shows that engines with different compression ratios have different NO emissions. Since NO emissions were higher in engines with higher compression ratios, cylinder pressure, which increases with the compression ratio, can be concluded to play an important role. Diagram (b) illustrates that higher temperatures cause greater deviation in the curve, i.e. an increase in NO concentration can be said to have occurred. This means that engines with lower compression ratios achieve their maximum pressure values, and hence their maximum NO concentration, earlier. The same conclusion can be drawn from diagram (c) in which the curves of Engine 1 and 2 are seen to intersect due to Engine 1 having a lower compression ratio and thus achieving its peaks, which are also lower, earlier (Lalić et al., 2016).

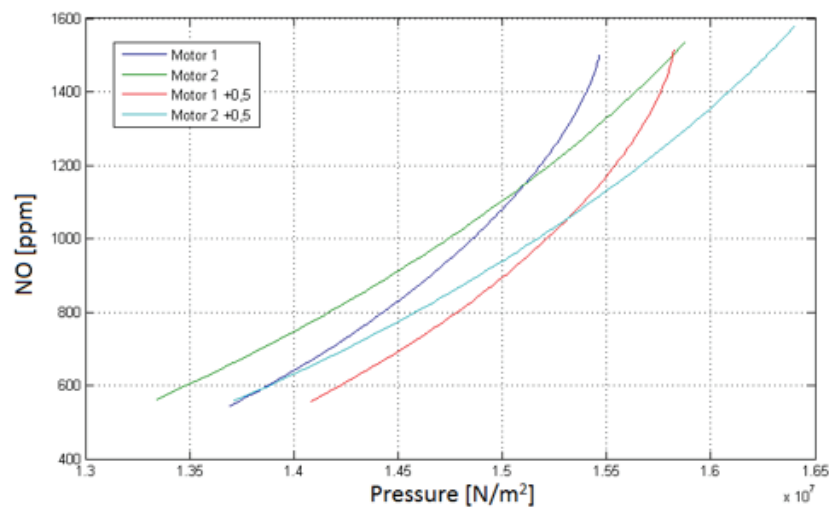

a)

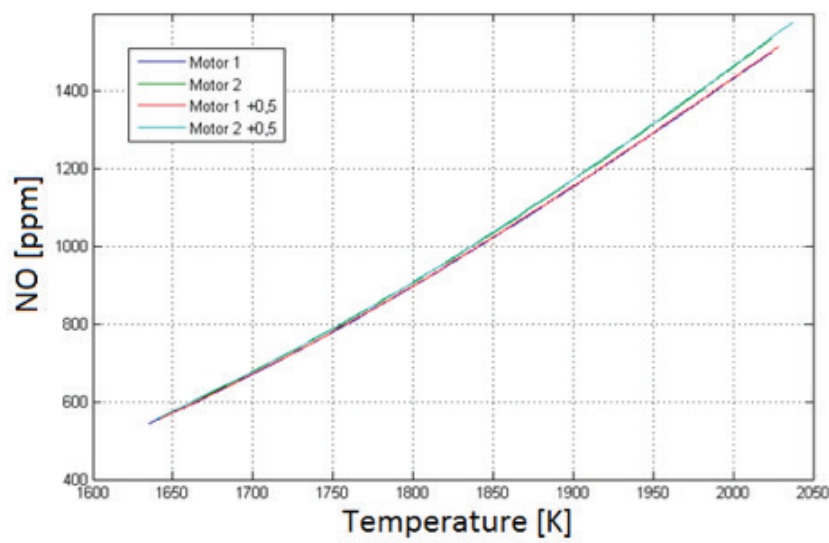

b)

Figure 8.

Nitrogen Oxide emissions: a) as a function of pressure with initial and modified compression ratios; b) as a function of temperature with initial and modified compression ratios.

To further clarify the impact of pressure on $\mathrm{NO}$ emission formation, Figure 9 (a) depicts NO emissions as a function of pressure for a wider range of temperatures inside the cylinder, 
i.e. for a wider range of pressures. The diagram suggests that high emission depends on pressure, where the pressure drop is still at a slight increase due to the temperatures still being high. Emission

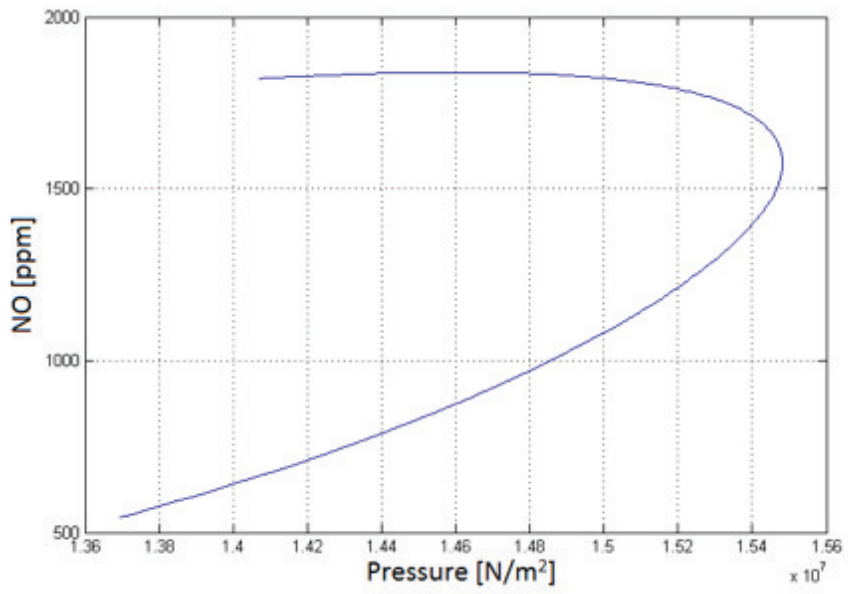

a) curves can be seen to start to decline with sharper pressure drop, since after achieving maximum pressures, temperatures begin to fall, reducing emissions.

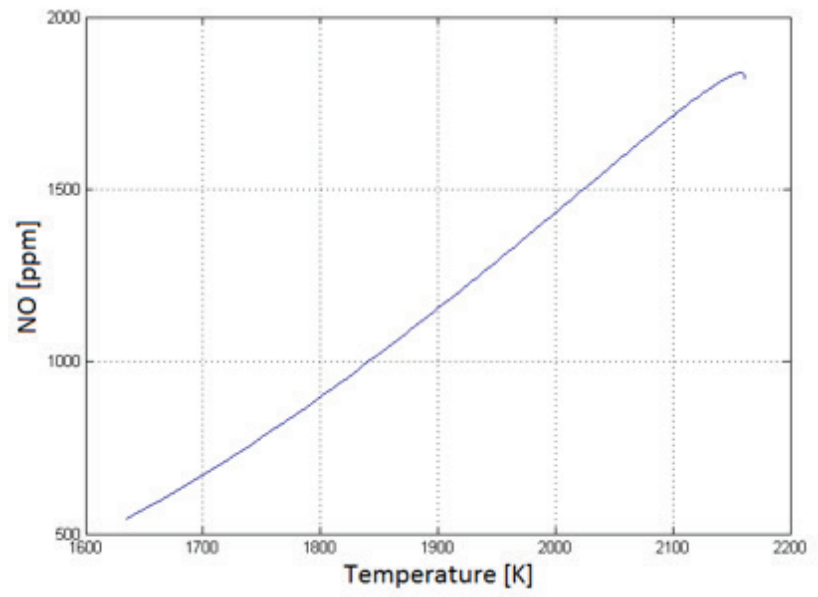

b)

Figure 9.

Nitrogen Oxide emissions: a) as a function of pressures; b) as a function of temperature.

The diagram in Figure 9 (b) likewise illustrates emissions for a wider range of temperatures inside the cylinder. At the very end of the emission curve where maximum temperature is reached, the beginning of emission decline can be observed. Huge impact of pressure are evident. Although temperatures in the cylinder are still high, nitrogen oxide emissions are lower due to low pressure and decreasing temperature (McAllistar et al., 2011).

\section{EXPERIMENTAL SECTION}

This section presents emission values obtained by test bed measurements of the MAM B\&W 6S60MC engine, provided in Table 3.

Figure 10 shows the point on the simulation curve for the value obtained from the engine test bed at $100 \% \mathrm{MCR}$.

Table 3.

Exhaust emission data obtained by testbed measurements.

\begin{tabular}{llllllll} 
Time & $\begin{array}{l}\text { Power } \\
\text { \% kW }\end{array}$ & $\begin{array}{c}\text { Speed } \\
\% \text { rpm }\end{array}$ & $\begin{array}{l}\text { NOx } \\
\text { ppm }\end{array}$ & $\begin{array}{l}\text { CO } \\
\text { Ppm }\end{array}$ & $\begin{array}{c}\mathbf{C O}_{2} \\
\%\end{array}$ & $\begin{array}{c}\mathbf{O}_{2} \\
\%\end{array}$ & $\begin{array}{l}\text { HC } \\
\text { ppm }\end{array}$ \\
\hline $10: 27$ & $25 / 2064$ & $63 / 76.5$ & 982 & 30 & 3.92 & 15.3 & 54 \\
\hline $10: 56$ & $50 / 4720$ & $79 / 96.2$ & 1026 & 28 & 3.87 & 15.3 & 51 \\
\hline $11: 23$ & $75 / 6580$ & $91 / 109.8$ & 1059 & 40 & 4.07 & 15.09 & 57 \\
\hline $13: 20$ & $100 / 8631$ & $100 / 121$ & 883 & 51 & 4.25 & 14.85 & 66 \\
\hline
\end{tabular}




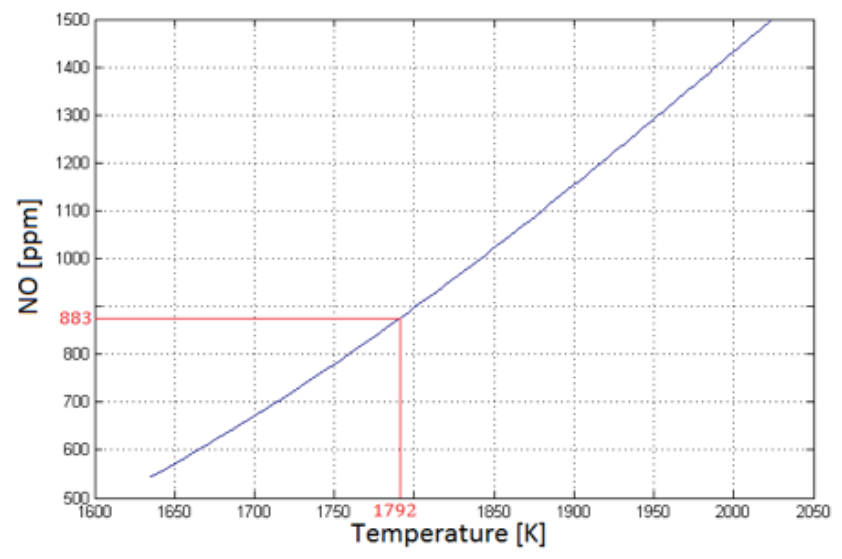

Figure 10.

Measured value in the NO emission diagram obtained by simulation model.

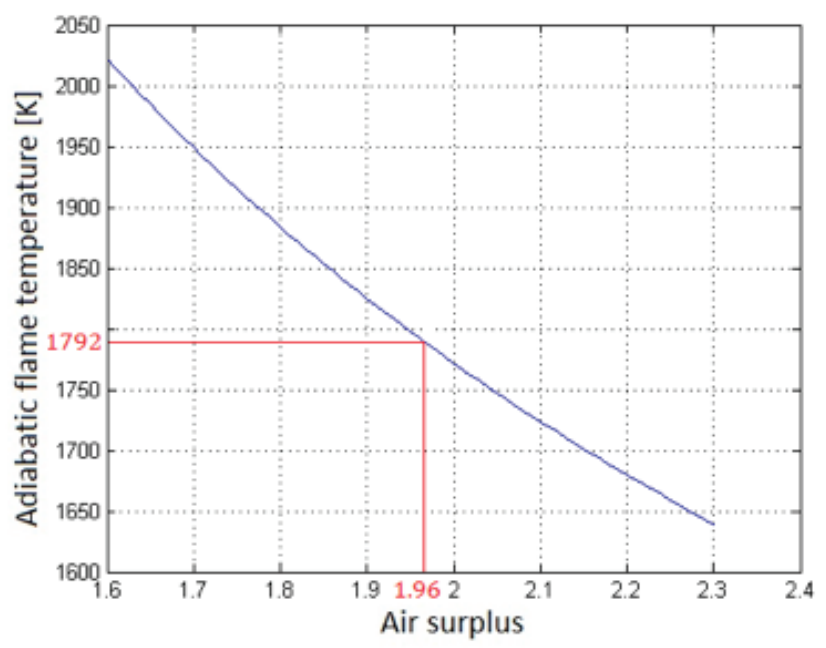

Figure 11.

Excess air for temperature indicated in measured values.

\section{CONCLUSIONS}

The need to preserve the environment is a major problem in the construction and production of slow speed diesel engines. Organizations such as the "IMO" and "EPA" set emission standards manufacturers are required to comply with. They must meet emission requirements while maintaining the same standard of performance. In this paper NOx emission was taken as the key parameter. Engine models were simulated, the obtained values analysed and compared with the actual tested values. In a developed computer program, NOx emissions were obtained by using simulated values and expressions for nitric oxides formation and compared with actual values. Air surplus, pressure, adiabatic flame temperature and compression temperatures were analysed to establish their effect on nitric oxides formation. The results showed air surplus reduction to increase temperature, since increased fuel mass $\left(m_{f}\right)$ increases heat. The diagrams depicting NOx emissions as a function of temperature and pressure do not only show the strong influence of temperature, but also an area in which NOx emissions decrease in spite of high temperature. This phenomenon is interpreted as a critical period in NOx formation. The rate of formation increases with the duration of combustion and an increase in pressure in the cylinder. Once maximum pressure is reached, the temperature of combusted gases decreases due to their mixing with cooler gases, resulting in the decrease of nitric oxides emissions.

\section{REFERENCES}

Andreadis, P., Chryssakis, C., Kaiktsis, L., (2009), Optimization of Injection Characteristics in a Large Marine Diesel Engine Using Evolutionary Algorithms, SAE Technical Paper 2009-01-1448.,

https://doi.org/10.4271/2009-01-1448

Benson, R. S., (1982), The Thermodynamics and Gas Dynamics of InternalCombustion Engines, Oxford: Clarendon Press.

Grljušić, M., Medica, V. and Račić, N., (2014), Thermodynamic Analysis of a Ship Power Plant Operating with Waste Heat Recovery through Combined Heat and Power Production, Energies, 7(11), pp. 7368-7394.,

https://doi.org/10.3390/en7117368

Grljušić, M., Medica, V., Radica, G., (2015), Calculation of Efficiencies of a Ship Power Plant Operating with Waste Heat Recovery through Combined Heat and Power Production, Energies, 8(5), pp. 4273-4299.,

https://doi.org/10.3390/en8054273

Guan, C., Theotokatos, G. and Chen, H., (2015), Analysis of Two Stroke Marine Diesel Engine Operation Including Turbocharger Cut-Out by Using a Zero-Dimensional Model, Energies, 8(6), pp. 5738-5764.,

https://doi.org/10.3390/en8065738

Heywood, J. B., (1988), Internal Combustion Engine Fundamentals, New York: McGraw-Hill.

Komar, I. and Lalić, B., (2015), Sea Transport Air Polution, in: Nejadkoorki, F. (ed.), Current Air Quality Issues, Rijeka: InTech, pp. 165-202.,

https://doi.org/10.5772/59720

Lalić, B., Komar, I. and Nikolić, D., (2014), Optimization of Ship Propulsion Diesel Engine to Fulfill the New Requirements for Exhaust Emission, Transactions on Maritime Science, 3(1), pp. 20-31.

https://doi.org/10.7225/toms.v03.n01.003

Lalić, B., Radica, G. and Račić, N., (2016), Analysis of Exhaust Gas Emission in the Marine Two-stroke Slow-speed Diesel Engine, Brodogradnja, 67(3), pp. 17 - 35., https://doi.org/10.21278/brod67302

Larsenb, U., Pierobona, L., Baldib, F., Haglinda, F. and Ivarsson, A., (2015), Development of a Model for the Prediction of the Fuel Consumption and Nitrogen Oxides Emission Trade-Off for Large Ships, Energy, 80, pp. 545-555.,

https://doi.org/10.1016/j.energy.2014.12.009 
McAllistar, S., Chen, J-F., and Fernandez-Pello, A. C., (2011), Fundamentals of Combustion Processes, New York: Springer-Verlag

Radica, G., (2008), Expert System for Diagnosis and Optimization of Marine Diesel Engines, Strojarstvo, 50(2), pp. 105-116.

Saravanan, S., Nagarajan, G., Anand, S. and Sampath, S., (2012), Correlation for Thermal NOx Formation in Compression Ignition (CI) Engine Fuelled with Diesel and Biodiesel, Energy 42 (1), pp. 401-410.,

https://doi.org/10.1016/j.energy.2012.03.028

Scappin, F., Stefansson, S. H., Haglind, F., Andreasen, A. and Larsen, U., (2012), Validation of a Zero-Dimensional Model for Prediction of NOx and Engine Performance for Electronically Controlled Marine Two-Stroke Diesel Engines, Applied Thermal Engineering, 37, pp. 344-352.,

https://doi.org/10.1016/j.applthermaleng.2011.11.047
Spahni, M., Schumacher, B. and Karamitsos, A., (2015), Concepts, Testing and First Service Experience with the Generation X-Engines, WinGD Low-speed Engines Licensees Conference, Interlaken, available at: https://www.wingd.com/ media/1435/marcspahni_generation-x-engines.pdf, [accessed 12 January 2017.].

Stoffels, G. G. M., (1999), Nitric Oxidein a Diesel Engine: Laser-Based Detectionand Interpretation, Profesor thesis, Katholieke Univesiteit Nijmegen, available at: https:// www.utwente.nl/en/et/thw1/People/Professors\%20and\%20senior\%20staff/staff/ stoffels/Thesis\%20Genie.pdf, [accessed 12 January 2017.].

Varbanets, R. A. and Karianskiy, S. A., (2012), Analyse of Marine Diesel Engine Performance, Journal of Polish CIMAC, 7(1), pp. 269 - 296. 